Original Article

\title{
A Cross sectional study to determine the prevalence of Diabetes Mellitus and its household awareness in the rural field practice areas of a medical college in Mangalore - A Pilot Study
}

\author{
Agnes Moira Preethi D'Souza ${ }^{1}$, Rashmi Kundapur ${ }^{2} \&$ N. Udaya Kiran ${ }^{3}$ \\ ${ }^{1}$ Postgraduate, ${ }^{2}$ Professor, ${ }^{3}$ Professor \& HOD, Department of Community Medicine \\ K.S. Hegde M edical Academy, Nitte University, M angalore, Karnataka, India. \\ Correspondence \\ Agnes Moira Preethi D'Souza \\ Post Graduate, Department of Community M edicine, K.S. Hegde M edical Academy, \\ Nitte University, M angalore - 575 018, Karnataka, India. \\ E-mail : moiradr06@gmail.com
}

\begin{abstract}
Introduction: Diabetes mellitus is a major clinical and public health problem accounting for 4.6 million deaths annually world-wide ${ }^{(1)}$. According to the recent World Health Organization report (WHO), India today leads the world with over 32 million diabetic patients and this number is projected to increase to 79.4 million by the year $2030^{(2)}$. The recent surveys indicate that Diabetes now affects a large part of the population i.e. 10-16\% of urban and 5-8\% of rural population in India ${ }^{(1)}$.

Objectives: This study aims at estimating the prevalence of diabetes, the household awareness, the pattern and regularity of health seeking behaviour among the households for diabetes.

Methodology: This cross sectional study was conducted among 40 households of Kuttar and Manjanady village of semi urban M angalore. Data was collected using a structured questionnaire after pre-testing. Questions on awareness were prio ritised, scored and then analysed. Likert scale wasused to grade the awareness score.

Results: Community prevalence of diabetes was found to be $7.7 \%$. Out of the total population $8.8 \%$ of males and $6.8 \%$ of females were diabetics. Among the diabetics male and female distribution was equal i.e. 50\%. Among the $7.7 \%$ of diabetics $50 \%$ of the subjects also had Hypertension. Awareness was average among $35 \%$ of the subjects. About $27.5 \%$ had poor score and $37.5 \%$ had very poor score for the awareness.
\end{abstract}

Conclusions: Community prevalence was low. Lifestyle modification was not present among Diabetics. Awareness was poor among the households.

Keywords: Diabetes M ellitus, Household awareness, Prevalence, Knowledge.

\section{Introduction}

Diabetes mellitus is a major clinical and public health problem accounting for 4.6 million deaths annually worldwide ${ }^{(1)}$. The burden of diabetes is increasing globally, particularly in developing countries. According to the recent World Health Organization report (WHO), India

Access this article online Quick Response Code

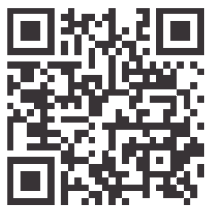
today leads the world with over 32 million diabetic patients and this number is projected to increase to 79.4 million by the year $2030^{(2)}$. The recent surveys indicate that Diabetes now affects a large part of the population i.e. $10-16 \%$ of urban and $5-8 \%$ of rural population in India ${ }^{(1)}$. NCDs like Diabetes are no longer only diseases of the rich, the old, and the sedentary. M oreover, it is becoming evident that NCDs, including their risk factors, are reflections of wider social, economic and environmental determinants, rather than simply a result of poor lifestyle 'choices' ${ }^{(3)}$. The quality of life is also greatly affected particularly in young adults, the group which is predicted to see the greatest increase in diabetes prevalence in developing countries. Because of such a speedy upsurge in the disease trend it is need of the day today for every person to be aware of the disease pattern, treatment available and complications. A literature search on knowledge about diabetes in developing countries 
yielded very few studies actually dealing with the awareness of diabetes among people with the disease. Data on awareness is of prime importance in formulating any kind of prevention strategy. This study aims at estimating the prevalence of diabetes, the household awareness, the pattern and regularity of health seeking behaviour among the households for diabetes.

\section{Materials and Methods}

This cross sectional study was conducted among 40 households of Kuttar and M anjanady village of semi urban Mangalore. Kuttar and Manjanady villages belong to the GramaKshema project which comes under the field practice area of KSHegde M edical Academy.

We included all 40 houses into the study who belonged to Grama Kshema Project. Selection of households for the project was based on their Socio economic status (lower and lower middle class were preferred. But if upper class was very much willing we included them) and willingness.

Data was collected using a structured questionnaire after pre-testing. Questionnaire had questions regarding onset of disease, duration, pattern of health seeking behaviour, drugs used, health facility accessed, lifestyle and diet modification was present or not. Questions regarding awareness were on the disease pattern, contributing factors, complications which can occur, steps taken to lower blood sugar. Questions on awareness were prioritised, scored and then analysed. All the correct answers with high priority were given the score 1.5. And the rest were given the score of 1 . All wrong answers were given the zero score. Total score ranged from 0-26. Likert scale wasused to grade the awareness score.

History of diabetes was taken from all aged above 18 years belonging to the family.

Awareness questionnaire was administered to any one family member of the household, aged above 18 years, present during the visit. The Individuals in the household were numbered from lower age group to higher age and random pick of number was done to select the sample. If that number was not present next present number was the sample.

The questionnaire was administered by the students pursuing II M BBS by a house to house interview method after adequate training.

All the data was entered in M SExcel and statistical analysis was done using SPSSsoftware.

\section{Results}

Among the 40 households, there were about 156 people who were above 18 years of age and out of them $7.7 \%$ were Diabetics (Fig 1), thereby making the community prevalence to be $7.7 \%$.

Out of the total population $8.8 \%$ of males and $6.8 \%$ of females were diabetics. Among the diabetics male and female distribution was equal i.e. $50 \%$. (Table 1 ) Most of the Diabetics were in the age group 40-50 (33.3\%) and 6170 years (33.3\%). Age distribution of diabetics is shown in figure 2 .

Among the $7.7 \%$ of diabetics $50 \%$ of the subjects also had Hypertension.

Half of the diabetics in the study were diagnosed 0-5 years prior to the present study. The duration since diagnosis of Diabetes is shown in Figure 3. Among the diabetics 91.7\% were regularly taking medications and $8.3 \%$ were not under treatment.

$8.3 \%$ of the diabetics visited health facility on weekly basis. $41.7 \%$ of the diabetics visited the health facility monthly. $25 \%$ of them visited health facility once in six months. Rest of the $25 \%$ visited health facility in irregular pattern.

$66.7 \%$ of the diabetics chose to go to private practitioners for their health needs. $25 \%$ diabetics got health care from KSHEM A. Rest of the $8.3 \%$ chose to go to a nearby PHC.

About $8.3 \%$ of the diabetics did not take any medication. (Table 2) About $58.3 \%$ of the diabetics used Sulfonylureas for their glycaemic control.16.7\% of them used M etformin for the treatment. $8.3 \%$ of them used combination of 
Sulfonylurea and Metformin and rest 8.3\% of them used Insulin for their glycaemic control. (Figure 4)

About $66.7 \%$ of the diabetics did not follow any kind of exercise before diagnosis and remained the same even after diagnosis. $25 \%$ did physical activity for 2.5 hours in a week and remained the same even after diagnosis. 8.3\% did exercise for 5 hours per week and remained the same even after diagnosis. $75 \%$ of the diabetics had modified their diet after diagnosis, whereas $25 \%$ of them remained the same.

Awareness was average among $35 \%$ of the subjects. About $27.5 \%$ had poor score and $37.5 \%$ had very poor score for the awareness. (Table 3)
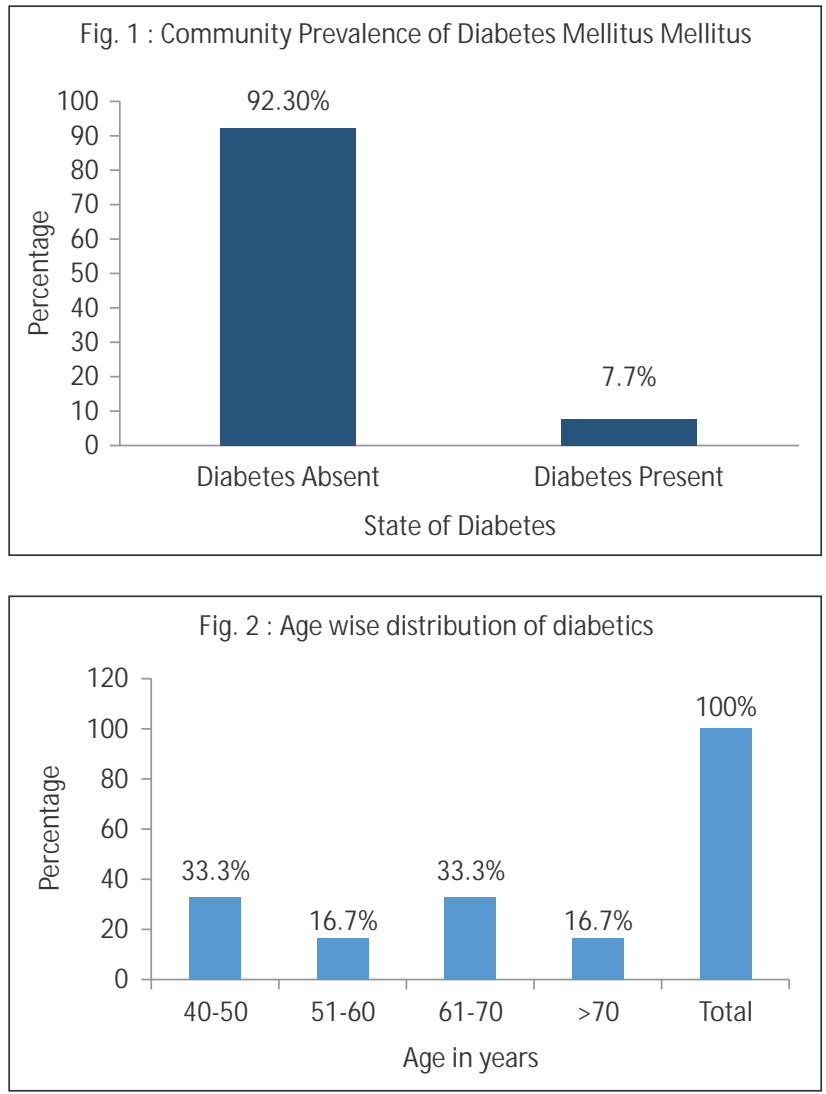

Table 1 : Table showing distribution of Diabetes according to gender

\begin{tabular}{|l|c|c|c|}
\hline \multirow{2}{*}{ Gender } & \multicolumn{2}{|c|}{ Diabetes } & Total \\
\cline { 2 - 3 } & Absent & Present & \\
\hline M ale & 62 & 6 & 68 \\
\hline Female & 82 & 6 & 88 \\
\hline Total & 144 & 12 & 156 \\
\hline
\end{tabular}
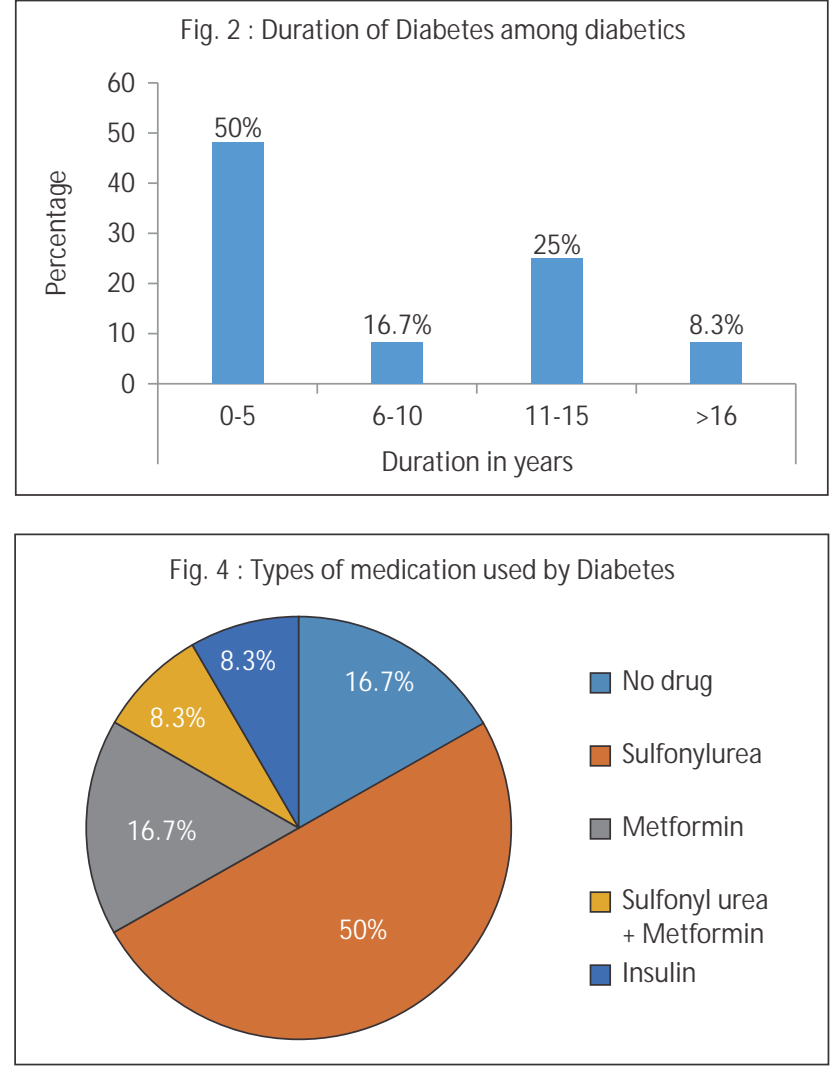

Table 2 : Health care facility utilisation among diabetics.

\begin{tabular}{|l|c|c|c|c|}
\hline Gender & $\begin{array}{c}\text { Private } \\
\text { Dispensary }\end{array}$ & $\begin{array}{c}\text { Near by } \\
\text { PHC }\end{array}$ & KSHEM A & Total \\
\hline Male & 5 & 1 & 2 & 6 \\
\hline Female & 5 & 0 & 1 & 6 \\
\hline Total & 8 & 1 & 3 & 12 \\
\hline
\end{tabular}

Table 3 : Table showing the awareness about diabetes among households

\begin{tabular}{|c|c|}
\hline Awareness & Percentage \\
\hline v poor & 27.5 \\
\hline Poor & 30.0 \\
\hline Average & 27.5 \\
\hline Good & 15.0 \\
\hline Total & 100.0 \\
\hline
\end{tabular}

\section{Discussion}

Our study shows the prevalence of Diabetes to be $7.7 \%$ which is less than study conducted by M uninarayana et al in Kolar district where they found it was about $10 \%{ }^{(4)}$. We found prevalence of Diabetes to be equal among males and females. But study by Muninarayana et al showed that prevalence was quite more among the males than females

i. e $71 \%$ and $29 \%$ respectively. A systematic review by Cheema et al ${ }^{(5)}$ shows the increasing rate of Diabetes with 
the increasing age, in this study too we find more of diabetics in the age group of $40-50$ and $60-70$ years.

More than $50 \%$ of the diabetics did not go for the regular check-up and consulted physician once in 6 months or more. Treatment seeking behaviour is better compared to the study by Muninarayana et al where only $9.7 \%$ of Diabetics went for regular check-up ${ }^{(6)}$. In our study M ore than half of the Diabetics preferred private practitioners over PHC's run by the government. About $66.7 \%$ of the Diabetics did not follow any kind of lifestyle modification even after diagnosis, when compared to study by M uninarayana et al where $54.8 \%$ of the Diabetics exercised regularly ${ }^{(6)}$.

Awareness about diabetes was found to be very poor. In this About $27.5 \%$ had poor score and $37.5 \%$ had very poor score for the awareness, which is much less when compared to the study done by Mohan Deepa et al in Chennai ${ }^{(7)}$ also they found $54 \%$ had more than average score for awareness but in our study only $35 \%$ had an average awareness about diabetes and none of them scored good or excellent for awareness.

\section{Conclusions}

Community prevalence of Diabetes Mellitus was comparatively low in our study population. Distribution of Diabetes was equal among males and females. Half of the Diabetics also had hypertension. Most of the Diabetics were compliant with the medication. M ost of them visited health facility on a monthly basis. M ost of them preferred private practitioners for treatment. Sulfonyl Urea's are the main source of drug they use. Most of them did not follow any kind of life style modifications even before or after diagnosis. Most of them did modify their diet after diagnosing with Diabetes Mellitus. Overall awareness about Diabetes wasfound low among the households.

\section{Recommendations}

We found that there is a great need for awareness on lifestyle modification and diet modification along with use of medications. Treating doctors should make a strong emphasis on lifestyle modification along with the usage of regular drugs.

Very poor awareness among the diabetics raises the huge need for increasing the awareness in the community, not only about diabetes but also about all other noncommunicable diseases. Awareness programmes can be conducted at the hospital and in the community to educate the patients about the need for physical activity, diet control and adherence to treatment. And also to educate the house holds about the common Non Communicable diseases and their complications.

M ost of the physicians concentrate drug therapy but do not give emphasis on lifestyle modifications, diet control, adherence to treatment, regular check-ups etc. which may be due to the time constraint that most doctors face nowadays.

Since it is a combined effort by the patient, treating doctor, family members and community they live in, efforts by all are necessary and equally important to reduce the burden of diabetes and also other non-communicable diseases.

\section{Acknowledgement}

The authors wish to thank Mr Santhosh, M r Ravi, medico social workers department of Community medicine and the all students of the second MBBS K S Hegde Medical Academy for helping during data collection.

\section{References}

1. Deepa M ohan, Deepa Raj, CSShanthirani, M anjula Datta, NCUnwin,A Kapur, V M ohan. Awareness and Knowledge of Diabetes in Chennai The Chennai Urban Rural Epidemiology Study [CURES - 9]. JAPI. 2005 April; 53:283-287.

2. Global status report on non-communicable diseases 2010[Internet].WHO; 2010 [Updated 2011 C; Cited 2015 Jan 7]. Available from: http://www.who.int/nmh/publications/ncd_report_ full_en.pdf.

3. Alessandro R Demaio12, Dugee Otgontuya, M aximilian de Courten, Ib C Bygbjerg, Palam Enkhtuya, Janchiv Oyunbileg and Dan W Meyrowitsch. Exploring knowledge, attitudes and practices related to diabetes in M ongolia: a national population-based survey. BM C. 2013; 13: 236 .

4. M Deepa, A Bhansali, RM Anjana, R Pradeepa, SR Joshi, PP Joshi, VK Dhandhania, PV Rao, R Subashini, R Unnikrishnan, DK Shukla, SV Madhu, AK Das, V Mohan, T Kaur. Knowledge and awareness of diabetes in urban and rural India: The Indian Council of Medical Research India Diabetes Study (Phase I): Indian Council of Medical Research India Diabetes 4. IJEM . 2014; 18: 3 ( 376 - 385).

5. Arsalan Cheema, Davies Adeloye, Simrita Sidhu, Devi Sridhar, and Kit Yee Chan. Urbanization and prevalence of type 2 Diabetes in Southern Asia: A systematic analysis. J Glob Health. Jun 2014; 4(1).

6. Muninarayana C, Balachandra G, Hiremath SG, Iyengar K, Anil NS Prevalence and Awareness regarding diabetes mellitus in rural Tamaka, Kolar. Int J Diabetes Dev Ctries. 2010 Jan; 30(1): 18-21

7. M ohan D, Raj D, Shanthirani CS, Datta M, Unwin NC, Kapur A, M ohan V. Awareness and Knowledge of Diabetes in Chennai - The Chennai Urban Rural Epidemiology Study [CURES - 9]. J Assoc Physicians India. 2005 Apr; 53: 283-7. 